\title{
Differentiated Instruction in Chinese Primary and Secondary Schools: A Systematic Literature Review
}

Meijie Bi ( $\sim$ meijie.bi@vub.be)

VUB: Vrije Universiteit Brussel https://orcid.org/0000-0003-2328-3712

Katrien Struyven

VUB University: Vrije Universiteit Brussel

Change Zhu

VUB University: Vrije Universiteit Brussel

\section{Research Article}

Keywords: Differentiated instruction, student diversity, Chinese primary and secondary schools, systematic literature review, student achievement

Posted Date: July 15th, 2021

DOI: https://doi.org/10.21203/rs.3.rs-207311/v1

License: (ㄷ) (i) This work is licensed under a Creative Commons Attribution 4.0 International License. Read Full License 


\section{Abstract}

This study aims to probe into the concepts and use of differentiated instruction (DI) in Chinese primary and secondary schools by means of a systematic literature review from 1995 to 2019 . Outcomes are presented in the form of thematic overview. Findings report that Chinese national conditions contributed to DI's definitions and theoretical basis from historical and realistic perspectives. Then, the selected articles show that Chinese teachers from primary and secondary schools are aware of the importance of student diversity, such as interests, learning style and abilities. Moreover, teachers can organize many teaching methods, like flexible grouping and collaborative learning, to build DI classrooms for satisfying various needs of learners. Results also point out DI's positive effect on students' achievement, but Chinese large class size and teacher incapability are the main obstacles to the implementation of DI.

\section{Introduction}

Differentiated instruction (DI) is not new to today's classroom (Tomlinson \& Allan, 2000). Unlike "one-size-fits-all" approach, DI emphasizes the learners' differences in readiness, interest and learning profile and the roles of teachers who can adopt various teaching measures to cater to student's needs (Tomlinson et al., 2003). A rationale for DI in the regular classroom is acknowledged through 40 years school experience in the field of education (George, 2005); by improving their own perceptions about DI, the teachers are able to adopt differentiated teaching methods and handle the differences of students with ease in the teaching process (Coubergs et al., 2017). DI is commonly known as a concept of teaching philosophy and praxis (Coubergs et al., 2017). DI is generally defined as "a pro-active, planned, and positive way to respond to students' differences in readiness, interests, and learning profiles by providing them with equal learning options" (Tomlinson, 2017). Therefore, teachers are encouraged to adopt DI in their daily teaching to embrace students' diversity (Schleicher, 2016).

A multicultural society shows the necessity of DI from an international view. There are several underlying reasons for it. Firstly, today's schools and classrooms put emphasis on various backgrounds of students, including interests, learning profiles, languages, ethics, abilities, preferences and so on (Arnaut et al., 2015). Secondly, as a "process of strengthening the capacity of the education system to reach out to all learners", inclusive education stresses "every learner matters and matters equally" (UNESCO, 2017), which requires teachers to offer equal opportunities to develop skills and knowledge by every student (Schleicher, 2016), as it is an educational movement that allows students with different needs to sit together in a regular classroom (OECD, 2010; Tomlinson, 2014). Additionally, for the purpose of narrowing down the gap between students with low and high academic performance, teachers should provide more support for struggling students (Bjork, 2005; Woolfolk, 2010), and previous literature has confirmed the positive effect of DI on improving students' learning outcomes (Firmender et al., 2013; McAdamis, 2001; Tieso, 2005; Tobin \& McInnes, 2008; Tulbure, 2011). Although the importance of $\mathrm{DI}$ is widely known in western countries, the concept of $\mathrm{DI}$ and its implementation in the Chinese context have not been much documented in English in the existing literature. As a developing country, China has its environment and historical culture for developing DI. Thus, based on Chinese DI-related studies conducted from 1995 to 2019 , a systematic literature review was presented to find out how Chinese teachers understood and implemented DI in actual daily teaching at primary and secondary schools. The research questions are as follows:

- What are the national conditions for developing DI in the context of Chinese primary and secondary schools?

- How did Chinese teachers define DI and which theories could support it?

- How Chinese teachers understand student diversity and organize teaching activities to achieve teaching objectives in classrooms?

- What was the effect of implementing DI and what were key barriers in teaching practices?

\section{Method}




\subsection{Search method}

By following rigorous procedures (Onwuegbuzie et al., 2010), literature with the term "DI" as the keyword in the title, abstract or the keyword was firstly searched from Chinese National Knowledge Infrastructure (CNKI), and the search controller was set to retrieve studies in full texts which were published on top journals in Chinese. Since the earliest paper related to DI was published in 1995, this point of time was designed as the origin of searching the literature. According to the PRISMA flow chart (Moher et al., 2009), Fig.1 shows different periods of the review process. 72 studies were identified through a systematic search from the database (i.e., CNKI) by following the procedures. After removing duplications, a total of 62 papers were screened, and 44 of them met the inclusion criteria during the selection process: (1) publication in Chinese between 1995 and 2019; (2) taking place at primary or secondary schools' classroom in the Chinese context. Next, 44 extant studies were read in detail, which led to another 15 publications being excluded. As a result, the number of finalized samples was 29. The exclusion criteria in this phase are (1) academic journal reports; (2) studies irrelevant to the role of teachers during DI teaching practice; and (3) the conceptual and empirical studies in which do not provide definition, theory and framework of DI or its organizational classroom ways and implementation effect. To organize essential information from specified articles, Table 1 was created to show the following study characteristics: author, year, research design, research background, participants, and research aim.

\subsection{Research sample}

This review discusses 29 papers published in 15 journals between 1995 and 2019. More than half $(n=18)$ of the included studies were published from 2005 to 2013, indicating that scholars began to pay more attention to DI in this period. Only three articles are empirical studies, implying Chinese experts prefer to write conceptual papers.

\section{Results}

\subsection{Overall description of the reviewed studies}

According to Hirschheim (2008), conceptual studies mainly highlight assumptions, axioms and premises, and heavily rely on previous studies. As shown in Tables 1 and 2, 26 conceptual articles explained the whole national conditions (7) for developing DI in Chinese primary or secondary schools, like the historical reason and social learning background. In addition to definitions (6) and theoretical support (8) of DI, teaching approaches (23) for organizing DI and eliminating barriers occurring (4) in practice are demonstrated in a form of thematic overview. Each article did not just focus on one topic, so points were overlapped between those studies. In the same way, empirical articles aimed to gain new knowledge by collecting and analyzing data based on experiments, surveys, observations, or interviews, instead of theories and principles. Three articles used a quantitative approach. The first one focused on the effect of improving cooking skills of students with disabilities through pre-test and post-test methods. The second one was to examine teachers' understanding of student diversity and ways of implementing DI, and the last study designed an instrument to test students' mathematics academic by tracking learners' daily learning performance inside and outside the classroom. The purpose of every article was summarized after being read carefully (see Table 1).

Table 1: Characteristics of the articles selected. 
B) Empirical articles: mainly gain new knowledge by collecting and analyzing data based on experiments, survey, observation or interview

Paper Article purpose

Zhao (2008) Research design: quantitative study;

Research method: quasi-experimental (pre-test and post-test of a single group);

Samples: 18 students with disabilities;

Research purpose: to explore whether DI helps improve students cooking skills

Liu (2017) Research design: quantitative study;

Research method: survey;

Samples: 1929 teachers from primary and secondary schools; Research purpose: to examine teachers' understanding and their behaviors about DI

Shi and GuoResearch design: quantitative study;

(2017) Research method: survey;

Samples: 219 students at Grade 6 from primary school;

Research purpose: to design an instrument with the guidance of DI to follow students' performance and examine its effect on Chinese Mathematics class

Table 2: Thematic overview of research outcomes 

conditions studies

\begin{tabular}{|c|c|c|c|c|c|c|}
\hline & 7 & 6 & 8 & 23 & 3 & 4 \\
\hline 3ng (2005) & $\mathrm{X}$ & & $\mathrm{X}$ & & & \\
\hline$\overline{\mathrm{ng}(2005)}$ & $\mathrm{X}$ & & $\mathrm{X}$ & $\mathrm{X}$ & & \\
\hline $\bar{a} \&$ Li (2006) & $\mathrm{X}$ & $\mathrm{X}$ & $\mathrm{X}$ & $\mathrm{X}$ & & \\
\hline \& Hua (2007) & $\mathrm{X}$ & & & $\mathrm{X}$ & & \\
\hline $\mathrm{a}(2007)$ & & & & & & \\
\hline \& Wei (2015) & $\mathrm{X}$ & $\mathrm{X}$ & & $\mathrm{X}$ & & \\
\hline$\overline{l(2018)}$ & $\mathrm{X}$ & & $\mathrm{X}$ & $\mathrm{X}$ & & \\
\hline$\overline{\mathrm{ng} \& \text { Cheng (2017) }}$ & $\mathrm{X}$ & & & $\mathrm{X}$ & & $\mathrm{X}$ \\
\hline $\operatorname{lg~J~(2008)~}$ & & $\mathrm{X}$ & $\mathrm{X}$ & & & \\
\hline$\overline{\lg (2007)}$ & & & & $\mathrm{X}$ & & \\
\hline a G (2019) & & $\mathrm{X}$ & $\mathrm{X}$ & & & \\
\hline$\overline{\mathrm{lg} \& \text { Hua (2004) }}$ & & $\mathrm{X}$ & $\mathrm{X}$ & $\mathrm{X}$ & & \\
\hline ang \& Zhang (2013) & & $\mathrm{X}$ & $\mathrm{X}$ & & & \\
\hline \& Zhu (1995) & & & & $\mathrm{X}$ & & \\
\hline $\mathrm{o} \mathrm{(2000)}$ & & & & $\mathrm{X}$ & & \\
\hline$\overline{\lg (2008)}$ & & & & $\mathrm{X}$ & & \\
\hline$\overline{\lg (2009)}$ & & & & $\mathrm{X}$ & & \\
\hline to (2014) & & & & $\mathrm{X}$ & & \\
\hline$\overline{o(2009)}$ & & & & $\mathrm{X}$ & & \\
\hline$\overline{\lg (2010)}$ & & & & $\mathrm{X}$ & & $\mathrm{X}$ \\
\hline$\overline{\lg (2010)}$ & & & & $\mathrm{X}$ & & \\
\hline$(2010)$ & & & & $\mathrm{X}$ & & \\
\hline an (2012) & & & & $\mathrm{X}$ & & \\
\hline$\overline{\operatorname{ang}(2011)}$ & & & $\mathrm{X}$ & $\mathrm{X}$ & & $\mathrm{X}$ \\
\hline$\overline{2016)}$ & & & & $\mathrm{X}$ & & \\
\hline$\overline{\text { ang (2013) }}$ & & & & $\mathrm{X}$ & & \\
\hline əng (2005) & & & & $\mathrm{X}$ & & \\
\hline$\overline{\text { 犭o (2008) }}$ & & & & $\mathrm{X}$ & $\mathrm{X}$ & \\
\hline$(2017)$ & & & & & $\mathrm{X}$ & $\mathrm{X}$ \\
\hline \& Guo (2017) & & & & & $\mathrm{X}$ & \\
\hline
\end{tabular}

Note: Capital X stands for the topic from research questions or the main goals of the article.

Table 3: Descriptive topics and features for approaches to organise DI 


Main Features Papers
approaches

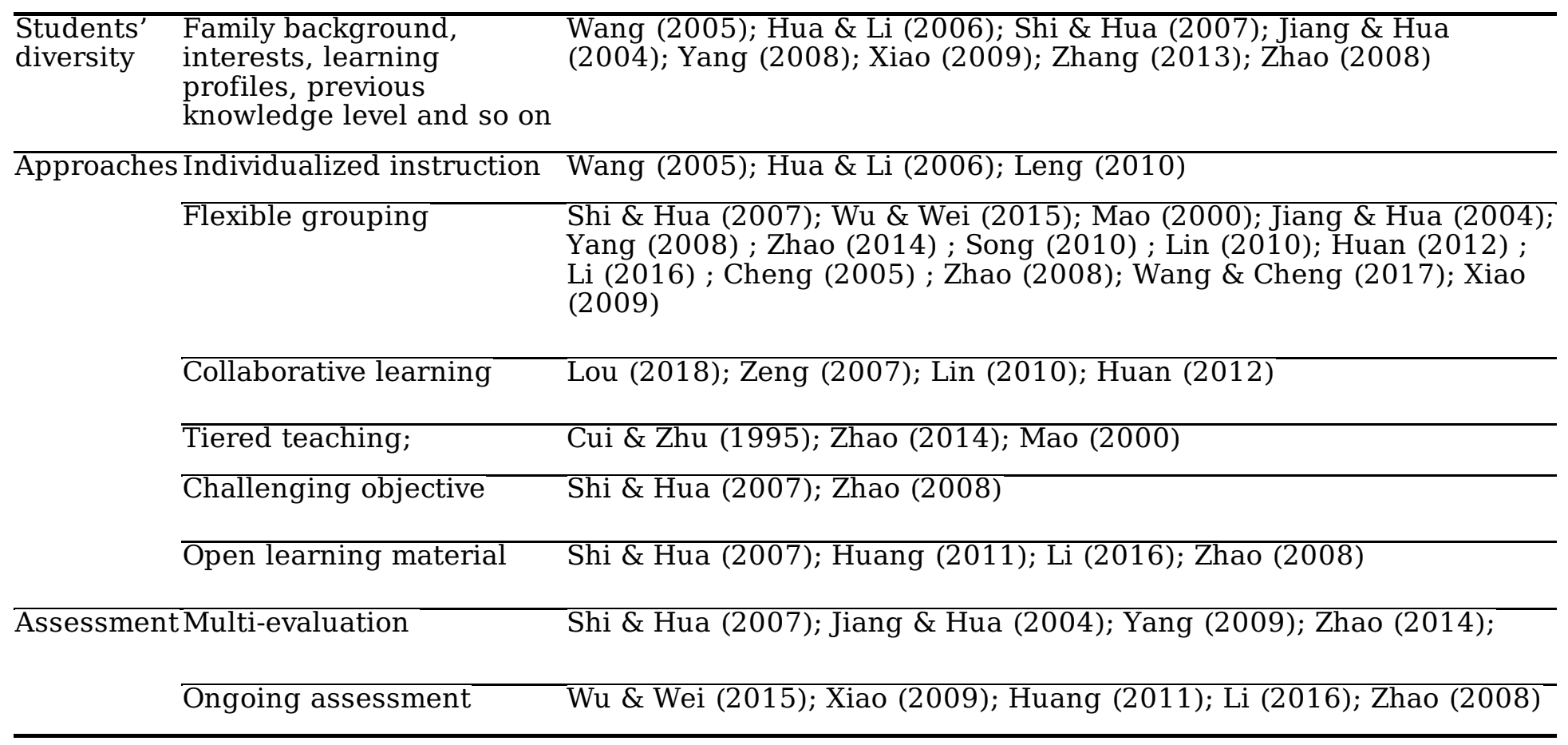

\subsection{Thematic overview}

One of the aims of this study is to find out how DI evolved in Chinese primary and secondary schools in past decades, including the national conditions for the implementation of DI. This study also hopes to explore DI's definition, theoretical basis and implementation in actual classroom. To further reflect on the results from reviewed studies, more detailed information is presented to describe different researching domains of DI in Chinese primary and secondary school context (see Table 2).

Almost every reviewed article aimed at achieving more than one goal and 6 different themes were finally summarized. The most important goals were to find out how Chinese educators understood DI and how they implemented DI in large-group size classrooms by adjusting different kinds of teaching contents and offering appreciate methods.

\section{RQ1: Chinese national conditions for implementing DI}

As a developing country, the national conditions in Chinese context differ from those of developed countries due to the differences in historical and social learning environments. Firstly, China has a long history of more than 5,000 years during which many famous educational experts emerged, like Confucius, who proposed that students should be given equal learning opportunities and that both female and male students were teachable (Tan, 2014). This valuable educational concept laid the foundation for the further development of DI in later times. He also emphasized that teachers should adapt their teaching based on students' own characteristics (Lam et al., 2002). Till now, Confucian beliefs about teaching for all by ignoring distinctions among students in the social class are still popular (Carless, 2012). Then, providing students with student-centered instructional ways and better accommodating learner diversity in a regular classroom setting are key areas in the recent curriculum reform in Chinese primary and secondary education, where educational equity and the tapping of students' potentials are stressed and promoted by the government educational 
policy (Cheng, 2005; Lou, 2018; Wang, 2005). Moreover, with the development of urbanization, more and more students were following their parents who were working in towns or cities and moving into town or city schools (Wu \& Wei, 2015). As a result, the class size in urban schools became larger, increasing the difficulty for the teachers to meet the vast needs of learners (Hua \& Li, 2006).

As a predecessor who introduced the item of DI to China around 2000, Hua G argued that the essence of DI was developed on Confucian beliefs and it was matching with the requirements of Chinese educational curriculum reform which called for improving the educational quality of primary and secondary schools, and underlining education fairness (Shi \& Hua, 2007). Importantly, implementing DI in the large-sized classroom asked teachers to regard differences in students as a kind of teaching resources. In this way, teachers could offer various teaching contents and activities to cater to the request of everyone by taking advantage of student variance, which was helpful in maintaining learners' diversity and improving student's achievement at local schools (Lou, 2018). Besides, DI was a proper instruction to meet the special demands for students with disabilities in a regular setting (Hua \& Li, 2006).

\section{RQ2: Definition studies and theory support of DI}

DI from Chinese expert, Hua, means that (1) every student differs from each other; (2) teachers could differentiate instructions by making use of those differences in students in the context of large class size; (3) it can fully tap students' potentials on their original basis in classroom teaching; (4) it is important for instructors to adopt proper teaching contents, teaching activities and assessment means (Hua, 2001). Although many Chinese educators thought the concept of DI was from Confucius, the origin in English literature about this item from Tomlinson has been prevailing, who claimed that teachers should adapt their teaching in mixed classrooms to meet diverse needs of talents and struggling learners according to their readiness, interests and learning profiles (Tomlinson, 2014). Additionally, giving appreciate instructions for students based on their characteristics from Confucian beliefs was a shared idea by Chinese and western educators, such as Hua's, and Tomlinson's DI. Hence, distinguishing the similarities and differences among those ideas was quite necessary. The similar essence of these three different teaching concepts was to help teachers understand the learning of students and allow them to attain teaching aims (Jiang \& Hua, 2004; Zhang \& Zhang, 2013). But for difference, the major difference of Confucian's DI with those of Hua and Tomlinson is the number of students. DI from Hua was addressed and implemented in large class size, which is based on the current Chinese national conditions (Hua, 2001), while Confucian taught students in a small group since there was no "classroom" during the period when he was a teacher. DI from Tomlinson is adopted in western classroom, where there are around 25 students in a class (Tommy, 1989).

Regarding the theory support of DI in Chinese context, the first one was the inheritance and development of "teaching according to students' characteristics" from Confucian beliefs (Jiang \& Hua, 2004; Zhang \& Zhang, 2013). Here, Confucian thought students' differences lied in characteristic and interest (Tan, 2014). After that, instructors began to stress the importance of differences among learners. Except for differences of students in characteristic and interest, Hua supported in his book that students' differences were also shown in their intelligence, learning ability and learning style (Cheng, 2005; Hua, 2001), and teachers should adjust their teaching according to learners' strengths and weaknesses during actual teaching (Jiang \& Hua, 2004; Lou, 2018; Tomlinson, 2001; Wang, 2005; Zeng, 2008; Zhang \& Zhang, 2013). In this way, teachers could provide students with equal learning opportunities. However, the idea about intelligence and capability originated from multiple intelligences of Gardner's theory that highlighted eight intelligences and problem-solving abilities of students (Campbell \& Campbell, 1999; Gardner, 2021). Particularly, instructional techniques or framework based on Gardner's theory could offer students who cannot achieve success in the traditional way with minimization learning opportunities in the classroom and thus they may not feel lost at school (Gardner, 2021). Enriching classrooms with various techniques and assessment forms could bring out all students' potentials (Campbell \& Campbell, 1999; Green, 1999) 
Next, learners' previous knowledge level was considered seriously by teachers because it was a link among the learner's previous, current and potential development levels (Hua, 2001; Hua \& Li, 2006; Huang, 2011). This representative concept was much similar to the zone of proximal development of Vygotsky from western literature and it was defined as a development level attained when one learner engaged in social activities (Riddle \& Dabbagh, 1999; Subban, 2006). Only by positively interacting with experienced peers or teachers could learners maximize their zone of proximal development on the premise of current knowledge (Blanton, 1998; Riddle \& Dabbagh, 1999; Zeng, 2007); accordingly, for instructors, understanding what students already knew before a new knowledge or skill was introduced was a necessary step to get prepared for their teaching (Huan, 2012; Yang, 2008). It was teachers who played a role in mediating teaching contents and activities for allowing students to get their zone of proximal development (Huang, 2011; Yang, 2008).

\section{RQ3: Student diversity and approaches to organize DI}

Almost all teachers who received a survey from Liu (2017) were aware of the importance to understand student differences. Among 29 reviewed articles, nine articles were more representative, since they talked about student diversity in the following aspects. To begin with, teachers coped with those diversities in students in terms of their family background, including economic status, parental education, and parental attention. Researches showed that parent involvement mattered to students' academic achievement (Hill \& Tyson, 2009). Some families have poor support for pupils; for example, some children have to grow up with their grandparents since their parents go to major cities to make money (Hua \& Li, 2006; Wang, 2005), so these students do not get enough attention from their parents and most of the elders cannot help with students' learning. Therefore, teachers could present alternative schemes (i.e., individual tutoring for students who are living with the elders) to fit students' life situations (Wang, 2005). Then, when preparing for lessons, teachers could organize a pre-test for students before class to better understand learners' previous knowledge level, readiness, interests, ability and learning profile (Jiang \& Hua, 2004; Shi \& Hua, 2007; Xiao, 2009; Yang, 2008; Zhang, 2013; Zhao, 2008). Next, classroom observation and communication with students face to face were also effective for instructors to know learners, on account of getting an intuitive understanding (Shi \& Hua, 2007; Wang, 2005; Wang \& Cheng, 2017).

Regarding approaches to organize $\mathrm{DI}$, a teacher tried to give a whole class a great experience by adopting various approaches in a typical classroom so as to reach all of them. However, in Chinese large-sized class, it was a great challenge for the teacher to care about everyone (Leng, 2010; Wang, 2005). Many schools thought individualized instruction was a supplement for DI, thereby offering extra after-class tutoring for advanced pupils and students who had difficulty in learning (Hua \& Li, 2006; Jiang \& Hua, 2004; Leng, 2010). In addition, for students with disabilities, those who sat together with normal ones in regular classrooms should receive more attention from teachers (Hua \& Li, 2006).

Flexible grouping was a main approach of DI because 14 out of 23 articles discussed it which aimed at exploring how teachers implement DI in the classroom (see Tables 2 and 3). When shifting from traditional "one size fits all" instruction to DI, teachers needed to know how to divide students freely into small groups, which was a clear symbol of DI. In the reviewed articles, the most popular method for grouping learners was to accord with their interests and abilities (Cheng, 2005; Lin, 2010; Mao, 2000; Wu \& Wei, 2015; Xiao, 2009; Yang, 2008; Zhao, 2014; Zhao, 2008), and the other methods showed how teacher group learners was based on their gender, learning need, readiness, learning profiles, and preknowledge level (Huan, 2012; Lin, 2010; Shi \& Hua, 2007; Xiao, 2009; Yang, 2008). Zhao (2014) and Li (2016) supported students to choose freely or randomly attending groups in terms of distance instead of being arranged by teachers. Next, four existing articles talked about grouping students in a homogeneous and heterogeneous way (Cheng, 2005; Huan, 2012; Shi \& Hua, 2007; Song, 2010). Switching between homogeneous and heterogeneous groups could improve their learning outcomes (Cheng, 2005; Huan, 2012). Moreover, learning in groups with homogeneity and heterogeneity could promote students to help each other (Huan, 2012; Shi \& Hua, 2007; Song, 2010). 
Collaborative learning and tiered teaching were popular among teachers working at primary and secondary schools. In Huan's research, she proposed that collaborative learning is helpful to building DI classroom by connecting different kinds of small groups with 2 to 6 students, which were divided in accordance with students' interests or abilities just like homogeneous and heterogeneous groups, temporary and permanent groups. Those were important forms of collaborative learning, which served the purpose of creating differentiation classroom and empowering students to learn from and help with each other (Huan, 2012). Lou (2018) also displayed positive results in his research about collaborative learning. He found that students' learning results could be maximized when they cooperated to finish tasks, and this finding was consistent with another two previous results, which highlighted the significance of learning in peer groups (Lin, 2010; Zeng, 2007). In contrast, tiered teaching was designed to pursue optional learning outcomes in a mixed classroom by grouping students based on their abilities (Cui \& Zhu, 1995; Mao, 2000; Zhao, 2014). Students were given different teaching contents, requirements, assessment, and homework (Mao, 2000; Zhao, 2014). Mao (2000) emphasized that teachers should adopt tiered teaching in the correct way since some students felt frustrated if they were divided into a group with lower academic performance.

It was necessary for teachers to take teaching contents and objectives into account when invoking various appropriate activities for students. Shi and Hua (2007) and Huang (2011) emphasized that opting for open learning material and setting up challenging learning objectives were meaningful for students' development. Those aims could be realized through optional courses, lots of learning resources, and multi-media (Shi \& Hua, 2007; Zhao, 2008). Zhao (2008) put forward that giving challenging learning objectives exerted a positive effect on students' zone of proximal development where they moved forward when given with greater challenge. In addition, Shi and Hua (2007), Huang (2011) and Zhao (2014) all held an opinion that the open learning material and appropriate leaning goals for students were beneficial to educational equity for the reason that every learner would make progress.

Last but not the least, multi-evaluation measures and ongoing assessment were stressed by teachers when they differentiated their instructions (Huang, 2011; Jiang \& Hua, 2004; Li, 2016; Shi \& Hua, 2007; Wu \& Wei, 2015; Xiao, 2009; Yang, 2009; Zhao, 2014; Zhao, 2008). Apart from the traditional assessment from teachers based on their performance of classroom context, homework and final examination, Shi and Hua (2007) and Yang (2009) felt that students were also a subject of assessment since they were familiar with their disadvantages. At the same time, students could get promoted from peer evaluations in a way of interacting with other classmates for the purpose of helping each other (Huang, 2011; Jiang \& Hua, 2004; Shi \& Hua, 2007). Zhao (2014), Wu and Wei (2015) also believed that encouragement played an important part in the assessment. Teachers should encourage students to experience what they were not good at and good at during the process of adapting to teaching, so students would gain more confidence to move ahead (Li, 2016; Xiao, 2009; Zhao, 2008).

\section{RQ4: Effects and barriers of DI}

Two empirical articles were conducted for testing whether students' performance improved or not, and the third one was carried out for understanding teachers' perceptions of and behaviors towards DI (see Table 1). Zhao (2008)implemented a quasi-experimental study by offering pre-test and post-test for 18 students with disabilities to explore whether DI helped improve students' cooking skills. Before starting an experiment, the researcher gave teachers a training about DI and this experiment lasted for one term. After accepting guidelines from teachers, every student made great progress during final examination, especially for those whose scores were the lowest ones in the pre-test. The other study created an instrument with the guidance of DI, whose effect was tested on Chinese and Mathematics at primary school by following students' learning trail (Shi \& Guo, 2017). The instrument included students' readiness, classroom performance, review and behaviour habit, and teachers scored according to the observation of students. After analyzing 219 students' learning behaviours about Chinese and Mathematics, their scores about the preview and classroom performance of Chinese were higher than those of Mathematics. The third study investigated 1,929 teachers from primary and secondary schools and 
examined their understanding of and behaviours towards DI (Liu, 2017). When implementing DI, results showed that (1) teachers agreed with the significance of $\mathrm{DI}$; (2) teachers had difficulty in diagnosing the learning profiles and characteristics of students while they put more value on students' knowledge barriers, interests, and independent learning; (3) around $50 \%$ of teachers paid their attention to one-third students and only $30 \%$ of teachers focused on the whole students; (4) teachers focused more on methods and strategies for organizing differentiated classrooms and less on teaching contents and DI tasks (Liu, 2017).

Concerning barriers, the classroom size remained as a major barrier. Wang and Cheng (2017) pointed out a common phenomenon that teachers dealt with more than 50 students in a class in urban schools, making it difficult for teachers to meet individual needs, and thus reducing interaction between teachers and students. The second barrier was that teachers were incapable of teaching students with DI according to the empirical research of Liu (2017). For example, it was found from data related to teachers' understanding about DI that teachers could not identify differences among students due to oversized class. Huang (2011) and Song (2010) also pointed out the problem of over-crowded students in one class. Besides, teachers were not able to set hierarchical teaching goals, homework, and answering ways for students of different academic performance levels. Additionally, another difficulty lied in the inability to let everyone take an active part in activities other than some or fewer students, owing to different levels and abilities of students (Song, 2010; Wang \& Cheng, 2017). Wang and Cheng (2017) called for teachers not only to give more chances to students with difficulties but also to encourage them to answer questions and devote more to class.

\section{Discussion}

The current study attempts to summarize the main aspects about DI implementation in Chinese primary and secondary schools through a systematic literature review of the articles published from 1995 to 2019, and results are organized from the view of Chinese national conditions for DI, definitions and theoretical support of DI, as well as approaches, effect and obstacles of of implementing DI in teaching practices. This review identified 29 publications, providing great value in understanding how mainland teachers perceive and implement DI in the national background of large class size. In addition, most existing researches in English about DI in Chinese societies are mainly from Hongkong and Taiwan instead of Chinese mainland school context where researches are documented in Chinese (Chien, 2015; Pan et al., 2017; Wan, 2016, 2017; Wu et al., 2015). As a result, this study fills the gap of researching DI in Chinese mainland primary and secondary schools, and it presents the information related to $\mathrm{DI}$, providing a reference for future researchers to understand Chinese DI progress in large class size. Moreover, this study is not only the first one written in English based on Chinese national conditions (i.e., large class) but also in a view of the systematic literature review.

In addition to lots of similarities, DI implementation is also quite different in Chinese and English literature according to the analytical results of studies related DI. Hence, both common issues from Chinese with international literature and special issues about DI unique to Chinese literature are discussed in the following part.

\subsection{Common issues about DI both in Chinese and English literature}

The first common issue about DI both in Chinese and English literature is the essence of definition. Both literatures acknowledge the fact that student differences are inherent in the classroom setting and then teachers differentiate instructions according to those differences in learners. The second one is the theory support of DI in Chinese and western schools' context. The zone of proximal development of Vygotsky (1980) and multiple intelligences of Gardner's theory (Campbell \& Campbell, 1999; Gardner, 2021) are seen as theories for DI (Tomlinson et al., 2003), in addition to human brain research, which is a rationality for DI from Tomlinson, since it suggests three concepts that cannot be ignored by teachers when differentiating their class (Tomlinson \& Kalbfleisch, 1998). Those concepts include safe learning environment, moderated challenges, and significant interactions with teachers, which are regarded as important factors for students to go ahead under their previous development (Tomlinson \& Kalbfleisch, 1998).

Page 10/19 
The third common issue is the approaches to implement DI. Both Chinese and western experts recognize the necessity of DI and they are more likely to consider implementing it in the following steps. Firstly, dealing with students' diversity. On the one hand, this can be realized through various organizational measures in Chinese, like flexible grouping by abilities, interests, readiness, and learning profiles (Cheng, 2005; Huan, 2012; Huang, 2011; Li, 2016; Wang \& Cheng, 2017; Xiao, 2009; Zhao, 2014; Zhao, 2008). Interestingly, flexible grouping can be seen as a key characteristic of DI, which is in line with documented English researches (Heacox, 2012; McQuarrie \& McRae, 2010; Tomlinson, 1995). Whitburn (2001) also confirmed the positive effect of different flexible grouping forms, while Tomlinson et al. (2003) pointed out the significance of variations between teachers' teaching and students' learning with different types of groups. Noticeably, switching between homogeneous and heterogeneous groups could improve students' learning outcomes (Belfi et al., 2012; Cheng, 2005; Huan, 2012; Terwel, 2005; Whitburn, 2001). On the other hand, teachers know about learners' differences by understanding student's family background. For instance, they are concerned whether there is the parental support for students' learning since every family is different (Hua \& Li, 2006; Wang, 2005). This is in agreement with the finding of previous studies: if parents pay more attention and offer more support, their kids will get promoted more easily (Fan et al., 2012; Karbach et al., 2013). Secondly, selecting appropriate teaching strategies and activities is beneficial to the building of differentiation, such as combining individualized instruction, tiered teaching and collaboration learning together to create an active involvement of learners (Cui \& Zhu, 1995; Lou, 2018; Wang, 2005; Zeng, 2007; Zhao, 2014). The above three ways are also recommended by Tomlinson (2014), Hattie (2005), Chance and Segura (2009) and Company (2010). Additionally, teachers should modify their teaching contents, strategies and activities, such as presenting alternative learning objectives, homework and ways to ask questions, in accordance with students' needs by observing their learning performance and monitoring their learning progress in daily teaching, at the same time ( $\mathrm{Li}$, 2016; Shi \& Hua, 2007; Xiao, 2009; Yang, 2008; Zhao, 2008), as what was found from McQuarrie and McRae (2010). Thirdly, since the major purpose of DI is to pursue the optimal outcomes for all, teachers need to think about showing different assessment standards for different levels of students according to their prior knowledge level (Jiang \& Hua, 2004; Thousand et al., 2007). Moreover, both Chinese teachers and western educators put their focus on giving different ways of appreciate feedback for students (Gijbels et al., 2005; Hattie, 2009), such as peer evaluation and ongoing assessment (Hattie, 2009; Jiang \& Hua, 2004).

The final issues are the effect and obstacles of implementing DI. By engaging in empirical studies at home and abroad, researchers identified a desirable effect in many studies. One Chinese researcher found improved cooking skills of students with disabilities with the help of teachers who conducted an exploratory research by adopting DI (Zhao, 2008). The other researcher designed a DI-based instrument and examined its use by following learners' leaning trails. After analyzing the score assessed by instructors through the observations of students' classroom behaviours, higher average scores in Chinese were found than those in Mathematics (Shi \& Guo, 2017). Similarly, better academic performances also were shown in the researches about DI implementation from Tulbure (2011), Baumgartner et al. (2003), and Miller (1990). What is more, differentiation resulted in higher achievement in a specific subject, like reading (Firmender et al., 2013), Mathematics (Chamberlin \& Powers, 2010; Tieso, 2005). However, teachers who adopt DI in class are faced with many tasks (Moore \& Kirkland, 2007; Tomlinson, 2001). It could be seen from the third Chinese empirical research about teachers' perceptions of and their behaviours towards DI that Chinese teachers had difficulty in detecting student's diversity, like learning profiles; only $30 \%$ of teachers could care about all students in a class (Liu, 2017), which is consistent with the results of western researchers, who found that teachers could not tell learners' differences, such as current development level, abilities, and family background (Moore \& Kirkland, 2007; Tomlinson, 2001). In addition to student diversity, there are lots of uncertainties when teachers implement differentiation, such as, whether teachers group students based on their abilities, interests, or gender, whether teachers make teaching objectives, give more attention to talents or disadvantaged ones, provide easier homework to certain students or not (Heacox, 2012; Watts-Taffe et al., 2012). Therefore, how teachers implement DI is related to the professional competence they have gained from learning, training, and experience. The third empirical study also displayed that 
teachers are not capable of designing and creating differentiation classrooms, including dealing with student variation and switching between many teaching approaches freely (Liu, 2017), which is in good agreement with international articles (George, 2005).

\subsection{Special issues about DI in Chinese literature}

In the first place, the Chinese national conditions are a major objective but special issue, and it has its own characteristics from two aspects. One is the historical factor, since Confucian beliefs have laid a foundation of DI development (Hua, 2019). The other is the call of educational equity. As the gap between cities and rural areas grows, the government makes great efforts to offer equal learning opportunities for every child in the current large-sized classroom (Cheng, 2005; Hua \& Li, 2006; Wang, 2005). However, the objective educational challenge in western countries is to prepare for all students within a multicultural society, along with the increase of religion, languages, and ethics (Arnaut et al., 2015; Belfi et al., 2012). Accordingly, DI is regarded as a good way to deal with the diversity of students in a classroom and maximize their learning (Tomlinson, 2001).

In the second place, as for Chinese DI definition, a Chinese expert, Hua G, gained insights from western educators' opinions about DI definition and combined it with the Chinese present situation, like urbanization and large class size. Hence, he put forward a different definition of DI in Chinese primary and secondary school context (Hua, 2001). What is more, it is worth mentioning that the inheritance and development of Confucius beliefs also make contribution to Chinese DI and it is Confucius beliefs that originally purpose students differences in characteristic (Jiang \& Hua, 2004; Zhang \& Zhang, 2013).

Finally, the most important special issue about DI in Chinese literature is the contextual factor, namely the large class size. According to the educational report of Chinese government (Chen, 2018), there are two types of large class size in Chinese primary and secondary schools. One is the super class size with more than 66 students and the number of such classes is 86,000 , accounting for $2.4 \%$ of all classes. The other is the large class size with more than 56 students and the number is 368,000 , which occupies $10.1 \%$ of all classes. Breakthroughs were made in eliminating super large and large class size in 2017 . To be specific, 56,000 super large-sized classes were reduced, declining significantly by nearly $40 \%$; 82,000 largesized classes were decreased, with a drop of $18.3 \%$ compared with the previous years (Chen, 2018). However, working in such a large-sized class is a big task for teachers, since it takes them more time to maintain discipline and increase the interaction with students (Wang \& Cheng, 2017). Therefore, an urgent action is needed to solve the challenge of large class size (Bjork, 2005; Subban, 2006).

To sum up, after analyzing reviewed articles $(n=29)$ selected in Chinese literature and comparing the DI implementation with that in English literature, some useful results are synthesized. Except for the Confucian beliefs, the essence of Chinese DI definitions is much similar with that from western expert Tomlinson $(2001 ; 2003)$ The same situation happens to the theory support for DI. Given the special issue about DI in Chinese primary and secondary schools, including Chinese national conditions and large class size, teachers are faced with difficulties when implementing DI in large-sized class, such as distinguishing learners' differences, adjusting teaching ways and tasks to meet demands of students with different knowledge levels. In addition, Chinese educators stress that the teaching content and style of assessment should be adapted according to the demand of students, which helps to cultivate all-around development of students. Instead of a pure pursuit for academic performance (Lou, 2018; Yang, 2009; Zhao, 2014), especially for students with learning difficulties, they hope to get positive feedback (Li, 2016; Wu \& Wei, 2015; Zhao, 2014). Importantly, teachers are able to adopt many ways to organize DI activities, like tiered teaching, flexible grouping and collaborative learning, and almost every teacher surveyed supports the importance of adopting DI in class (Liu, 2017). However, compared with the DI development in western literature, the number of empirical researches about DI in Chinese schools is much less and there are no advanced instruments to measure teachers' perceptions of and practices about DI with the guidance of 
theoretical models in Chinese. Promisingly, the mature concepts and practical guidelines about DI from western literature can be connected with Chinese studies in practices in the future.

\section{Implications, Limitations And Conclusions}

As the first review of researching DI progress in Chinese mainland primary and secondary schools, this study offers a way to help the international research community understand Chinese DI. Both Chinese and English literature show the theoretical implications in definitions and theoretical basis, which gives audiences a general picture about DI. This study also displays the theoretical implications from DI definitions and the theoretical inheritance of Confucius in the context of Chinese primary and secondary schools. Apart from that, for practical implications approaches, obstacles, and effect of DI from conceptual and empirical studies are summarized. This review discusses common ways to implement DI not only in an international academic society but in special Chinese national conditions, like large class size, in which most teachers cannot provide equal opportunity for every student.

The first limitation is the number of empirical articles. Only three empirical studies were selected in this review for the reason that most articles in Chinese literature are conceptual papers, which just depend on the perceptions and ideas from authors. More attention should be paid to empirical studies in the future work. The other limitation is the style of writing this review, which is the systematic literature review. All results are synthesized in a form of main topics. The other writing style, like meta-analysis review, should be tried to get more interesting results.

The purpose of this review is to find out how Chinese teachers view and implement DI in primary and secondary schools with the consideration of national conditions. Thanks to Confucian beliefs, the definition and theory support of Chinese DI differ from DI described in English literature. However, both have the same essence of their connotation (i.e., respecting student differences and maximizing learning outcomes of learners). Then, as China is a developing country with rapid urbanization, the number of students sitting in one class in towns and cities here is increasing. Consequently, how to provide every student with equal learning opportunities is a challenge for Chinese teachers (Wang, 2005), although Chinese government has been focusing on educational equity since 2001 when the second-round curriculum reform was started and important educational policy highlighting student-centered approaches in classroom teaching was promulgated and implemented (Chen, 2018). Because of this contextual factor, teaching in super large or large class size cannot be avoided and previous studies show that teachers are incompetent for working in such a large class size, like adjusting teaching contents and diagnosing students' diversity. Therefore, it is necessary to look for ways to help teachers work better. Moreover, based on this study, empirical studies about DI should be caused concern from Chinese experts who put more focus on theoretical studies. It is suggested that they connect modern theoretical models and practical guidelines in western literature with Chinese DI practice to develop more Chinese specialty about DI.

\section{Declarations}

The authors declare no competing interests.

\section{References}

Arnaut, K., Blommaert, J., Rampton, B., \& Spotti, M. (2015). Language and superdiversity. Routledge.

Baumgartner, T., Lipowski, M. B., \& Rush, C. (2003). Increasing Reading Achievement of Primary and Middle School Students through Differentiated Instruction.

Belfi, B., Goos, M., De Fraine, B., \& Van Damme, J. (2012). The effect of class composition by gender and ability on secondary school students' school well-being and academic self-concept: A literature review. Educational research review, 
$7(1), 62-74$.

Bjork, C. (2005). Indonesian education: Teachers, schools, and central bureaucracy. Routledge.

Blanton, M. (1998). Prospective teachers emerging pedagogical content knowledge during the professional semester. Unpublished Doctoral Dissertation. North Carolina State University.[Online] http://www. ncsu.

edu/crmse/research_papers/blanton. diss. doc [11 November, 2003].

Campbell, L., \& Campbell, B. (1999). Multiple intelligences and student achievement: Success stories from six schools. ASCD.

Carless, D. (2012). From testing to productive student learning: Implementing formative assessment in Confucian-heritage settings. Routledge.

Chamberlin, M., \& Powers, R. (2010). The promise of differentiated instruction for enhancing the mathematical understandings of college students. Teaching Mathematics and Its Applications: An International Journal of the IMA, 29(3), 113-139.

Chance, P. L., \& Segura, S. N. (2009). A rural high school's collaborative approach to school improvement. Journal of Research in Rural Education (Online), 24(5), 1.

Chen, B. (2018). 미 [large class size]. http://www.moe.gov.cn/jyb_xwfb/xw_zt/moe_357/jyzt_2018n/2018_zt07/zt1807_bzzs/201803/t20180320_330644.html

*Cheng, X. (2005).

Chien, C.-W. (2015). Influence of differentiated instruction workshop on Taiwanese elementary school English teachers' activity design. Theory and Practice in Language Studies, 5(2), 270-281.

Company, M. L. I. (2010). The MetLife survey of the American teacher: Collaborating for student success. ERIC Clearinghouse.

Coubergs, C., Struyven, K., Vanthournout, G., \& Engels, N. (2017). Measuring teachers' perceptions about differentiated instruction: The DI-Quest instrument and model. Studies in Educational Evaluation, 53, 41-54.

https://doi.org/10.1016/j.stueduc.2017.02.004

*Cui, T., \& Zhu, J. (1995). $\square$ [Shanghai Educational Research], 06, 33-35.

Fan, W., Williams, C. M., \& Wolters, C. A. (2012). Parental involvement in predicting school motivation: Similar and differential effects across ethnic groups. The Journal of Educational Research, 105(1), 21-35.

Firmender, J. M., Reis, S. M., \& Sweeny, S. M. (2013). Reading comprehension and fluency levels ranges across diverse classrooms: The need for differentiated reading instruction and content. Gifted child quarterly, 57(1), 3-14.

Gardner, H. (2021). Disciplined mind: What all students should understand. Simon \& Schuster.

George, P. S. (2005). A rationale for differentiating instruction in the regular classroom. Theory into practice, 44(3), 185193.

Gijbels, D., Dochy, F., Van den Bossche, P., \& Segers, M. (2005). Effects of problem-based learning: A meta-analysis from the angle of assessment. Review of educational research, 75(1), 27-61. 
Green, F. E. (1999). Brain and learning research: Implications for meeting the needs of diverse learners. EDUCATIONINDIANAPOLIS-, 119, 682-687.

Hattie, J. (2005). The paradox of reducing class size and improving learning outcomes. International journal of educational research, 43(6), 387-425.

Hattie, J. (2009). Visible Learning: A Synthesis of Over 800 Meta-Analyses Relating to Achievement. Taylor \& Francis. Heacox, D. (2012). Differentiating instruction in the regular classroom: How to reach and teach all learners (Updated anniversary edition). Free Spirit Publishing.

Hill, N. E., \& Tyson, D. F. (2009). Parental involvement in middle school: a meta-analytic assessment of the strategies that promote achievement. Developmental psychology, 45(3), 740.

Hirschheim, R. (2008). Some guidelines for the critical reviewing of conceptual papers. Journal of the Association for Information Systems, 9(8), 21.

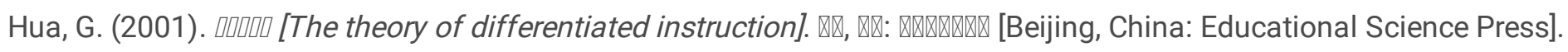
*Hua, G. (2019). 40(04), 114-117.

*Hua, G., \& Li, Z. (2006).

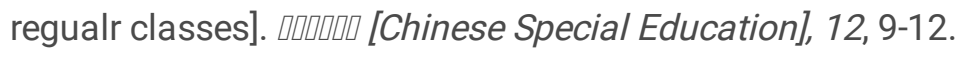

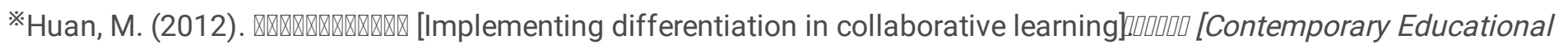
ScienceJ(16), 22-24.

*Huang, Y. (2011). class]. प०००० [Teaching and Management], 12, 122-123.

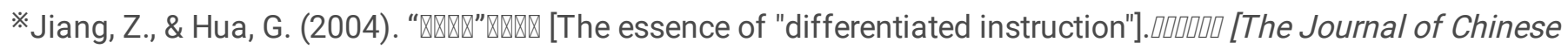
Education], 04, 54-57.

Karbach, J., Gottschling, J., Spengler, M., Hegewald, K., \& Spinath, F. M. (2013). Parental involvement and general cognitive ability as predictors of domain-specific academic achievement in early adolescence. Learning and Instruction, $23,43-51$.

Lam, C.-C., Ho, E. S. C., \& Wong, N.-Y. (2002). Parents' beliefs and practices in education in Confucian heritage cultures: The Hong Kong case. Journal of Southeast Asian Education, 3(1), 99-114.

*Leng, G. (2010). Educational Research](08), 72-73.

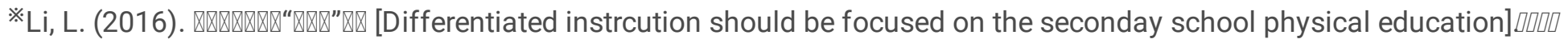
$\square[$ [The Journal of Chinese Education](2), 106.

*Lin, J. (2010). $\square$ [Audio-visual Education Research](05), 91-97. 
*Liu, G. (2017).

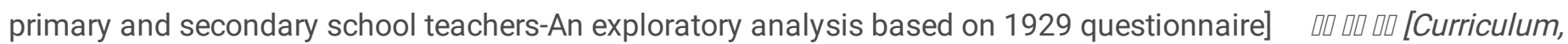
Teaching Material, Teaching Method], 37(12), 37-42+36.

*Lou, Z. (2018). प[ [Educational Science Research], 07, 65-68.

*Mao, J. (2000).

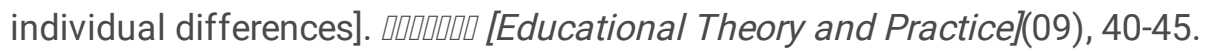

McAdamis, S. (2001). Teachers tailor their instruction to meet a variety of student needs. Journal of Staff Development, 22(2), $1-5$.

McQuarrie, L. M., \& McRae, P. (2010). A provincial perspective on differentiated instruction: The Alberta Initiative for School Improvement (AISI). Journal of Applied Research on Learning, 3(4), 1-18.

Miller, B. (1990). A review of the quantitative research on multigrade instruction. Research in Rural Education, 7(1), 1-8.

Moher, D., Liberati, A., Tetzlaff, J., Altman, D. G., \& Group, P. (2009). Preferred reporting items for systematic reviews and meta-analyses: the PRISMA statement. PLoS medicine, 6(7), e1000097.

Moore, D. S., \& Kirkland, S. (2007). Instroduction to the Practice of Statistics, Online Study Center with E-book \& Webassign. WH Freeman.

OECD. (2010). Educating teachers for diversity: Meeting the challenge. OECD.

Onwuegbuzie, A. J., Collins, K. M., Leech, N. L., Dellinger, A. B., \& Jiao, Q. G. (2010). A meta-framework for conducting mixed research syntheses for stress and coping researchers and beyond. GS Gates, WH Gmelch, \& M. Wolverton (Series Eds.) \& KMT Collins, AJ Onwuegbuzie, \& QG Jiao (Vol. Eds.), Toward a broader understanding of stress and coping: Mixed methods approaches, 169-211.

Pan, H.-L. W., Nyeu, F.-Y., \& Cheng, S.-H. (2017). Leading school for learning: Principal practices in Taiwan. Journal of Educational Administration.

Riddle, E. M., \& Dabbagh, N. (1999). Lev Vygotsky's social development theory. Retrieved June, 6, 2005.

Schleicher, A. (2016). Teaching excellence through professional learning and policy reform. Lessons from Around the World, International Summit on the Teaching Profession.

*Shi, M., \& Guo, S. (2017). evaluation studenrs' learning conditions based on the concept of differentiation-taking the practice of one school in

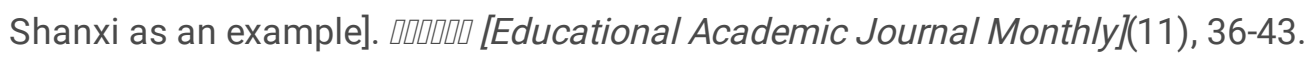

※Shi, Y., \& Hua, G. (2007). 40.

*Song, Y. (2010). प्र००० [Teaching and Management], 18, 147-148.

Subban, P. (2006). Differentiated instruction: A research basis. International education journal, 7(7), 935-947. 
Tan, C. (2014). Confucius. A\&C Black.

Terwel, J. (2005). Curriculum differentiation: Multiple perspectives and developments in education. Journal of Curriculum Studies, 37(6), 653-670.

Thousand, J. S., Villa, R. A., \& Nevin, A. I. (2007). Differentiating instruction: Collaborative planning and teaching for universally designed learning. Corwin Press.

Tieso, C. (2005). The effects of grouping practices and curricular adjustments on achievement. Journal for the Education of the Gifted, 29(1), 60-89.

Tobin, R., \& McInnes, A. (2008). Differentiating learning in the literacy classroom. Literacy, 42(1), 3-9.

Tomlinson, C. A. (1995). Deciding to differentiate instruction in middle school: One school's journey. Gifted child quarterly, 39(2), 77-87.

Tomlinson, C. A. (2001). How to differentiate instruction in mixed-ability classrooms. ASCD.

Tomlinson, C. A. (2014). The differentiated classroom: Responding to the needs of all learners. Ascd.

Tomlinson, C. A. (2017). How to differentiate instruction in academically diverse classrooms. ASCD.

Tomlinson, C. A., \& Allan, S. D. (2000). Leadership for differentiating schools and classrooms. Ascd.

Tomlinson, C. A., Brighton, C., Hertberg, H., Callahan, C. M., Moon, T. R., Brimijoin, K., Conover, L. A., \& Reynolds, T. (2003). Differentiating instruction in response to student readiness, interest, and learning profile in academically diverse classrooms: A review of literature. Journal for the Education of the Gifted, 27(2-3), 119-145.

Tomlinson, C. A., \& Kalbfleisch, M. L. (1998). Teach me, teach my brain: A call for differentiated classrooms. Educational leadership, 56(3), 52-55.

Tommy, T. (1989). Class size and public policy: Politics and panaceas. Educational Policy, 3(3), 261-273.

Tulbure, C. (2011). Do different learning styles require differentiated teaching strategies? Procedia-Social and Behavioral Sciences, 11, 155-159.

UNESCO, A. (2017). A guide for ensuring inclusion and equity in education. Geneva: UNESCO IBE. https://unesd oc. unesc o. org/ark:/48223/pf000, 2482, 7, Article 7.

Vygotsky, L. S. (1980). Mind in society: The development of higher psychological processes. Harvard university press.

Wan, S. W.-Y. (2016). Differentiated instruction: Hong Kong prospective teachers' teaching efficacy and beliefs. Teachers and Teaching, 22(2), 148-176.

Wan, S. W.-Y. (2017). Differentiated instruction: are Hong Kong in-service teachers ready? Teachers and Teaching, 23(3), 284-311.

*Wang, P. (2005).

*Wang, Y., \& Cheng, H. (2017).

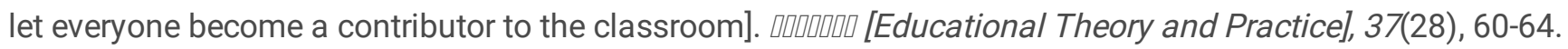


Watts-Taffe, S., Laster, B., Broach, L., Marinak, B., McDonald Connor, C., \& Walker-Dalhouse, D. (2012). Differentiated instruction: Making informed teacher decisions. The Reading Teacher, 66(4), 303-314.

Whitburn, J. (2001). Effective classroom organisation in primary schools: mathematics. Oxford Review of Education, $27(3), 411-428$.

Woolfolk, A. (2010). Educational Psychology. London: The Ohio State University: Pearson Education International.

Wu, C., Wan, S., \& Wong, Y. (2015). Exploring Hong Kong secondary school teachers' teaching beliefs on differentiated instruction. Teaching for tomorrow today, 158.

*Wu, C., \& Wei, Y. (2015).

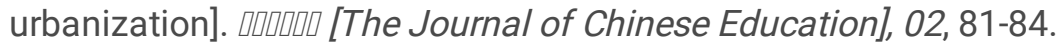

*Xiao, X. (2009). Educational Technology], 19(03), 42-45.

*Yang, L. (2008). $\square$ [Contemporary Educational Science](6), 56-58.

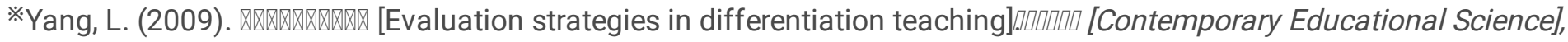
12, 15-17.

*Zeng, J. (2007). $\square$ [Educational Research], 08, 69-73+79.

*Zeng, J. (2008). instruction-On the historical source of the concept about differentiation and lessons for modern education] 00000 $\square$ [Educational Theory and Practice], 04, 52-56.

*Zhang, H. (2013).

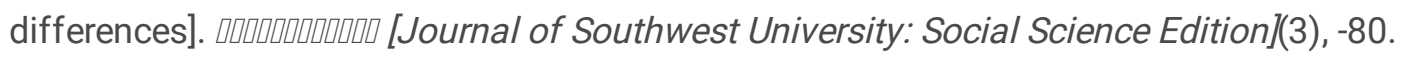

*Zhang, Q., \& Zhang, G. (2013). “ “Q concept about "Teaching Students in Accordance with Their Aptitudes"-Also focus on the ontological defense based on the teaching philosophy of Generative Theory] 000000 [Research on Higher Education], 34(08), 71-75.

※Zhao, L. (2014). Method], 34(04), 125.

*Zhao, X. (2008).

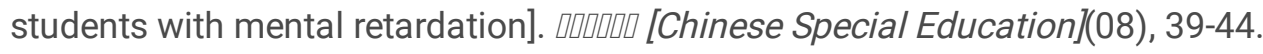

\section{Figures}




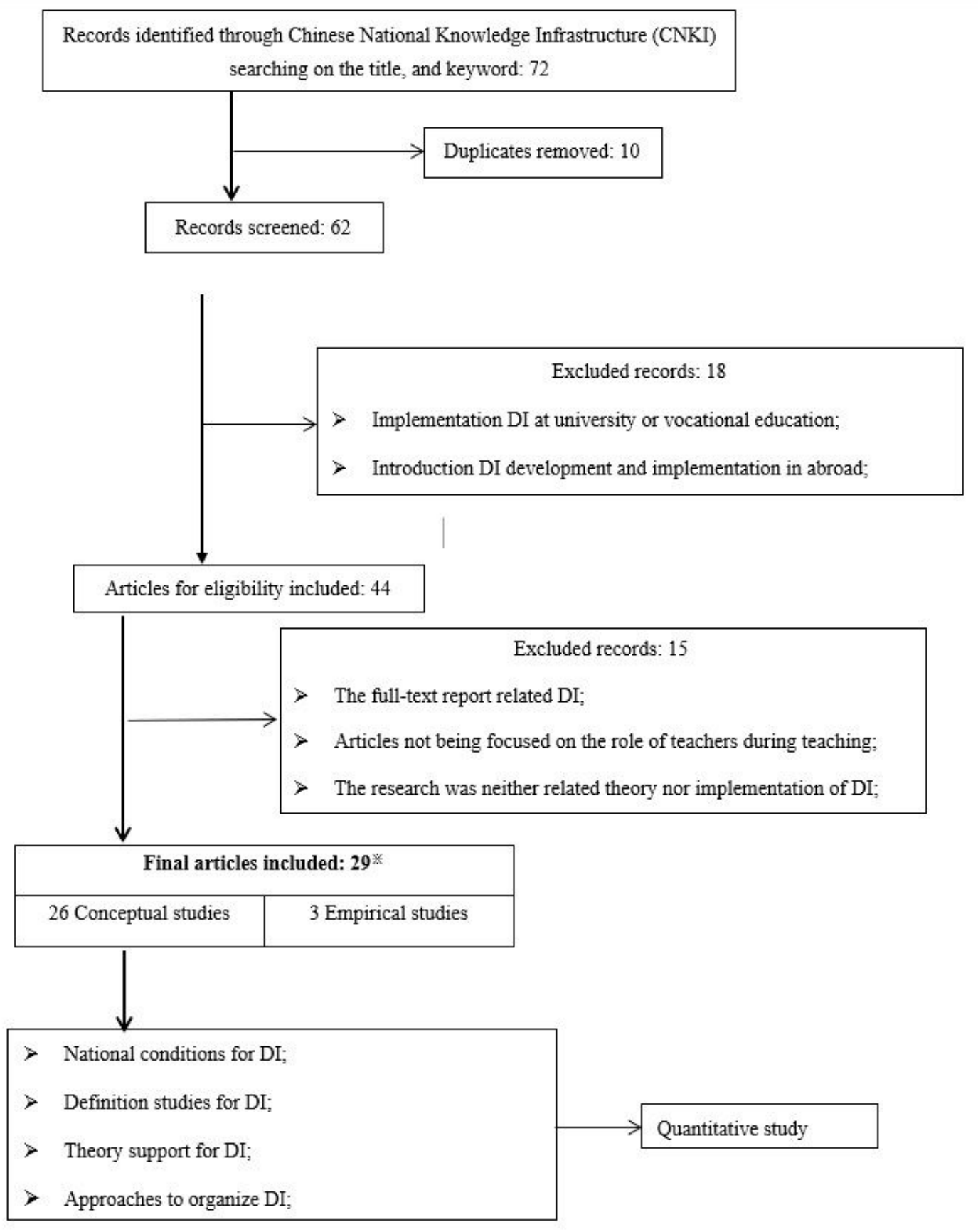

Figure 1

PRISMA flow chart of this systematic search. ※ These studies were noted in bibliography (see Table 1 for an overview). 